Article

\title{
Analysis of Rotor-Stator Interaction on the Aerothermal and TBC Insulation Performance of a Turbine Stage under Hot Streak Inlet Condition
}

\author{
Li Shi *, Yuanfeng Lu and Hanze Huang
}

Citation: Shi, L.; Lu, Y.; Huang, H. Analysis of Rotor-Stator Interaction on the Aerothermal and TBC Insulation Performance of a Turbine

Stage under Hot Streak Inlet

Condition. Coatings 2022, 12, 25

https://doi.org/10.3390/

coatings 12010025

Academic Editor: Narottam P. Bansa

Received: 20 August 2021

Accepted: 13 October 2021

Published: 27 December 2021

Publisher's Note: MDPI stays neutral with regard to jurisdictional claims in published maps and institutional affiliations.

Copyright: (c) 2021 by the authors. Licensee MDPI, Basel, Switzerland. This article is an open access article distributed under the terms and conditions of the Creative Commons Attribution (CC BY) license (https:// creativecommons.org/licenses/by/ $4.0 /$ )
School of Mechanical Engineering, Xiangtan University, Xiangtan 411105, China; xtulyf@126.com (Y.L.); xtuhhz@163.com (H.H.)

* Correspondence: shili@xtu.edu.cn; Tel.: +86-731-5829-2209

\begin{abstract}
Hot streaks and rotor-stator interaction have a great influence on the aerothermal performance of turbine blades. Previous investigations have conducted limited study of the film-cooled blade. To investigate the combined effects of a hot streak and rotor-stator interaction on the coated blade, an unsteady numerical simulation has been conducted with an efficient unsteady NavierStokes solver in this paper. The numerical results at four different relative stator-rotor locations $(t=0 / 4 T, 1 / 4 T, 2 / 4 T$, and $3 / 4 T)$ have been investigated in one stator period. Compared with the stator, rotor-stator interaction exerts a significant impact on the cooling performance of the rotor blade under hot streak inlet conditions. The overall cooling effectiveness distribution of the coated rotor blade is similar to that of the uncoated blades in one stator period. Relatively lower overall cooling performance of the rotor blade can be observed in the $1 / 4$ stator period. Then, the cooling performance begins to increase and relatively larger cooling effectiveness can be observed in the $3 / 4$ stator period. The addition of a TBC is generally beneficial to the improvement of blade surface cooling performance, especially for the areas with low overall cooling performance. However, a negative cooling effectiveness increment can be observed at the trailing edge. It shows that for an area with poor cooling performance, the addition of thermal barrier coating will have the opposite effect. Therefore, it is necessary to enhance the design of cooling arrangements at the trailing edge to maximize the insulation performance of TBCs for the coated rotor blade.
\end{abstract}

Keywords: hot streak; rotor-stator interaction; thermal barrier coatings; cooling effectiveness

\section{Introduction}

Due to the continuing demand for higher thermal efficiency, the turbine inlet temperature has far exceeded the melting point of the metal material [1-3]. Therefore, a cooling arrangement design is needed to guarantee safe running conditions for a gas turbine. For a typical internally cooled blade, the coolant passes through the internal channels to protect the blade and then forms a protective cooling film over the surface to defend the blade against the influence of an external hot stream [1-3]. Thermal barrier coatings (TBCs) are high-temperature-resistant coatings. They are deposited on the surface of the high-temperature-resistant metal to act as insulation for the base material, reducing the base temperature. For a typically coated blade, thermal barrier coatings (TBCs) block heat flux transfer from the external hot stream to the substrate metal surface [4-6].

Due to the limited gains from further improvement of internal cooling and film cooling performance, a typically advanced cooling arrangement design usually incorporates internal cooling, film cooling, as well as TBC techniques [4]. Although there are many studies on the influencing factors and their influencing mechanisms on the cooling performance of the uncoated vane or blade, there are few studies that have considered the coated vane or blade. Wang et al. [7] conducted unsteady numerical simulations on the film-cooled first-stage vane and blade of the GE-E ${ }^{3}$ engine HPT. The results showed that unsteady film cooling 
effectiveness fluctuations at the leading edge (LE) region are the most significant, with the mean-to-peak fluctuation amplitude reaching over $\pm 100 \%$. Liu et al. [8] studied the insulation characteristics of an internally cooled Mark II stator vane coated with multilayer TBCs. They concluded that coatings can benefit more from a decline in the average temperature than the maximum temperature. Prasert et al. [9] researched the influence of the mainstream turbulence intensity on the overall cooling effectiveness of a film-cooled stator vane coated with a one-layer coating. Their work indicated that the coating effect is more significant under a higher mainstream turbulence intensity. Tang et al. [10] investigated the temperature distribution and thermal-stress field of an internally cooled stator vane coated with a one-layer coating. Their research indicated that the dangerous regions may be located on the suction side of the stator vane. Shi et al. [11] used numerical simulation analysis of the combined influences of film cooling and TBCs on the cooling performance of a film-cooled C3X stator vane. They concluded that TBCs show simultaneous positive and negative roles in improving cooling performance. In addition, enhancement of the internally convective heat transfer of the vane structure is guaranteed to maximize the insulation performance of TBCs for the coated stator vane. In the studies that have been performed, more attention has been placed on the influence of mainstream temperature, turbulence intensity, and film cooling on the overall cooling performance under the uniform temperature inlet condition. However, for a typical gas turbine, the temperature distribution shows significant non-uniformity both in radial and circumferential directions [12]. For typical military engines, the maximum temperature of the hot streak (HS) can reach up to 1.24 of the mass-averaged temperature $[12,13]$. Considering the turbine inlet temperature has far exceeded the melting point of the metal material, a $25 \mathrm{~K}$ under-prediction of temperature may cause a halving of its life span. Therefore, it is important to understand the influence of hot streak migration mechanisms in the turbine stage to guarantee safe running conditions for the gas turbine. There is some literature that has studied the effect of the hot streak on the turbine aerothermal performance for an uncoated vane or blade. Mansouri et al. [14] investigated numerically the effect of the intensity of the swirling flow combined with the temperature non-uniformity hot streak on the aerothermal performance of a nozzle guide vane. The results showed that the hot streak with the swirl undergoes twisting following the orientation of the swirl. Basol et al. [15] analyzed the effect of the hot streak clocking position on the heat load of a rotor blade. Their work found that circumferential temperature distribution at the combustor exit can lead to considerable spanwise heat load distribution on the rotor blade. Wang et al. [16] carried out the unsteady computational study of hot streaks at different turbulence intensities and different circumferential positions. They found that the hot streak's relative position affects not only the airfoil surface temperature variations but also the vane and blade mid-span HTC. Wang et al. [17] studied the combined effect of the hot streak and the swirling flow on the cooling performance of rotor blades. They concluded that the heat transfer environment of rotor blades shows great differences with different inlet swirl directions.

In the studies that have been performed, more attention has been placed on the uncoated vane. Information on the influence on the coated stator vane and the coated rotor blade is still less common in the open literature, especially for the coated rotor blade [18-21]. For the coated rotor blade, a wide variety of factors are known to contribute to the complexity of aerothermal and TBC insulation performance, which include the hot streak, the residual swirl, high levels of mainstream turbulence and unsteadiness, rotational effects, and rotor-stator interaction [22-26]. The present work focuses on the combined effects of a hot streak and rotor-stator interaction. Unsteady numerical simulation has been conducted with an efficient unsteady Navier-Stokes solver. The combined effects on the rotor blade at four different relative rotor-stator locations $(t=0 / 4 T, 1 / 4 T, 2 / 4 T$, and $3 / 4 T$, where the $T$ is the stator period) are investigated to reveal the TBCs' insulation characteristics and the cooling performance of the coated blade. The motivation of this work is trying to provide a guideline for the design of the cooling arrangements to maximize the insulation performance of TBCs under the hot streak inlet condition. 


\section{Numerical Methods}

\subsection{Mesh Generation and Calculation Techniques}

In this paper, a domain scaling method has been applied to decrease computational resources. The computational domain contains one stator vane and two rotor blades. The stator vane is an internally cooled C3X vane; see in Figure 1a. The axial chord length $\left(C_{a x}\right)$, the axial chord length height, and the designed outlet airflow angle are $78.16 \mathrm{~mm}, 77.22 \mathrm{~mm}$, and $72.38^{\circ}$, respectively $[21,22]$. The diameter of No. 1-7 cylindrical cooling channels is $0.063 \mathrm{~mm}[21,22]$. In addition, the diameters of No. 8-9 and No. 10 cooling channels are 0.31 and $0.198 \mathrm{~mm}$, respectively [21,22]. The rotor blade is a film-cooled VKI blade; see in Figure 1b. The axial chord length and the designed inlet airflow angle are $80 \mathrm{~mm}$ and $30^{\circ}$, respectively [26]. To examine the effects of the hot streak on the TBCs' insulation performance, a layer of thermal barrier coating with a thickness of $0.52 \mathrm{~mm}$ is mounted on the external surface of the substrate metal [9]. Three cylindrical cooling channels located in the front portion of the rotor blade feed cooling air to the film cooling holes on the leading edge (LE), the pressure side (PS), and the suction side (SS), which have 3, 2, and 1 rows of film cooling holes, respectively. Specific geometric parameters of cooling channels are shown in Table 1 . The computational domain extends $1.5 C_{a x}$ upstream toward the stator vane and $1.5 C_{a x}$ downstream toward the rotor blade [26]. The computational domain and mesh are shown in Figure $2 \mathrm{a}, \mathrm{b}$, respectively. The material properties are shown in Table 2.

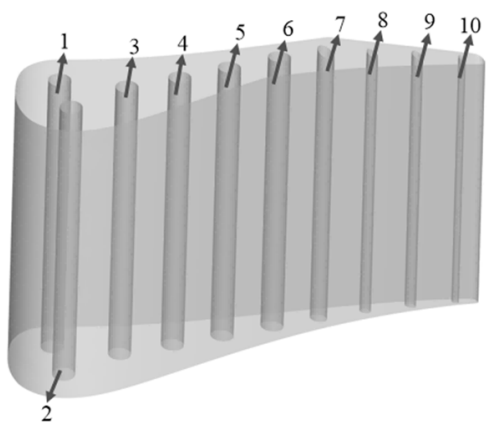

(a)

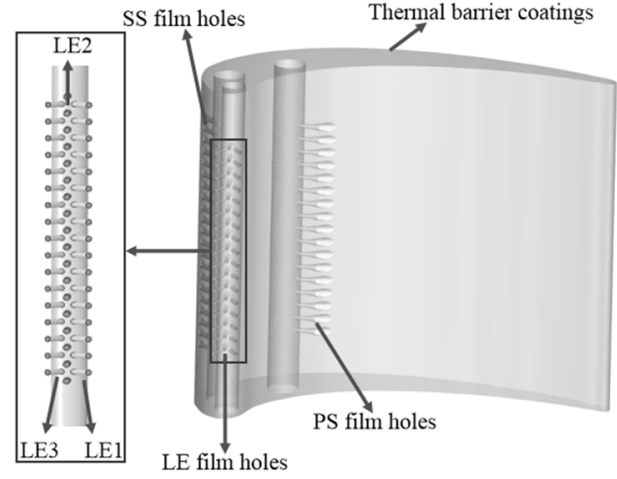

(b)

Figure 1. Stator vane and rotor blade. (a) C3X vane; (b) VKI blade.

Table 1. Geometric characteristics of cooling channels.

\begin{tabular}{ccc}
\hline Cooling Channel & Diameter $(\mathbf{m m})$ & Film Cooling Hole Count \\
\hline Leading edge & 4.5 & $17+18+18(52$ cylindrical $)$ \\
Suction side & 6 & $21+20(41$ shaped $)$ \\
Pressure side & 6 & $17(17$ shaped $)$ \\
\hline
\end{tabular}

Table 2. Material properties.

\begin{tabular}{ccc}
\hline Material & Parameter & Value \\
\hline \multirow{3}{*}{ Gas } & Density $\left(\mathrm{kg} \cdot \mathrm{m}^{-3}\right)$ & Ideal gas assumption \\
& Specific heat capacity $\left(\mathrm{J} \cdot \mathrm{kg}^{-1} \cdot \mathrm{k}^{-1}\right)$ & $938+0.196 \mathrm{~T}$ \\
& Thermal conductivity $\left(\mathrm{W} \cdot \mathrm{m}^{-1} \cdot \mathrm{K}^{-1}\right)$ & $0.0102+5.8 \times 10^{-5} \mathrm{~T}$ \\
Substrate metal & Density $\left(\mathrm{kg} \cdot \mathrm{m}^{-3}\right)$ & 8055 \\
& Specific heat capacity $\left(\mathrm{J} \cdot \mathrm{kg}^{-1} \cdot \mathrm{k}^{-1}\right)$ & $438.5+0.177 \mathrm{~T}$ \\
& Thermal conductivity $\left(\mathrm{W} \cdot \mathrm{m}^{-1} \cdot \mathrm{K}^{-1}\right)$ & $11.2+0.0144 \mathrm{~T}$ \\
TBCs & Density $\left(\mathrm{kg} \cdot \mathrm{m}^{-3}\right)$ & 5500 \\
& Specific heat capacity $\left(\mathrm{J} \cdot \mathrm{kg}^{-1} \cdot \mathrm{k}^{-1}\right)$ & 418 \\
& Thermal conductivity $\left(\mathrm{W} \cdot \mathrm{m}^{-1} \cdot \mathrm{K}^{-1}\right)$ & 1.04 \\
\hline
\end{tabular}


In this paper, the unsteady numerical simulation has been conducted with an unsteady compressible RANS solver ANSYS FLUENT 18.2. Considering the compressibility of the gas under large environmental pressure, both the mainstream air and the cooling air have been defined as the ideal compressible gas [22]. The density meets the ideal gas molecule assumption. Considering the huge temperature differences between the mainstream and cooling air, both molecular viscosity and thermal conductivity are considered as the functions of temperature and Sutherland's law is used to evaluate the influence of temperature on thermal parameters of the gas. The specific heat capacity is fitted with a temperature polynomial that is based on the physical parameter curve of the gas. The turbulence is solved by the realizable $k-\varepsilon$ model, which is suitable for the calculation of the strong rotational flow and the separation of the boundary layer inside the gas turbine stage. To accelerate the convergence of the iteration procedure, the pressure and velocity coupling meet the SIMPLE algorithm. To improve calculation accuracy, the momentum equation and the energy equation are adopted in a second-order upwind style. To decrease the convergence time of the steady-state calculation, the steady numerical results are used as the initial value for the unsteady numerical simulation. The rotational speed of the rotor blade is $2700 \mathrm{rpm}$ [23]. The inlet-mass-averaged total pressure and the mass-weighted average temperature are $213.286 \mathrm{kPa}$ and $818 \mathrm{~K}$, respectively, with a uniform turbulence intensity $\mathrm{Tu}$ of $8.0 \%$ [25]. The boundary conditions are shown in Table 3. To study the effect of the inlet hot streak, the circumferentially averaged profile of total temperature is fitted by the experimental data in polynomial form; see in Figure 3. The normalized temperature ratio $\theta\left(T / \overline{T_{0}}\right)$ of the hot streak is about $1.04[25,26]$. The boundary conditions for cooling air are shown in Table 2. For the film-cooled VKI rotor blade, the overall mass-weight ratio and the temperature ratio of the cooling air to the mainstream are $3 \%$ and 0.5 , respectively [23]. The cooling air is split through the leading edge, the suction side, and the pressure side into $40 \%, 35 \%$, and $25 \%$, respectively [23]. A sliding mesh method is adopted for rotor-stator interface treatment. Both sides of the calculation domain are set as rotation periodic boundaries [25]. The end-walls are set as insulation wall surfaces [26]. The physical time steps for each stator period (the period of the rotor blade passing through one stator vane pitch) are 128. Steady sub-iterations of 20 steps are selected for each physical time step.

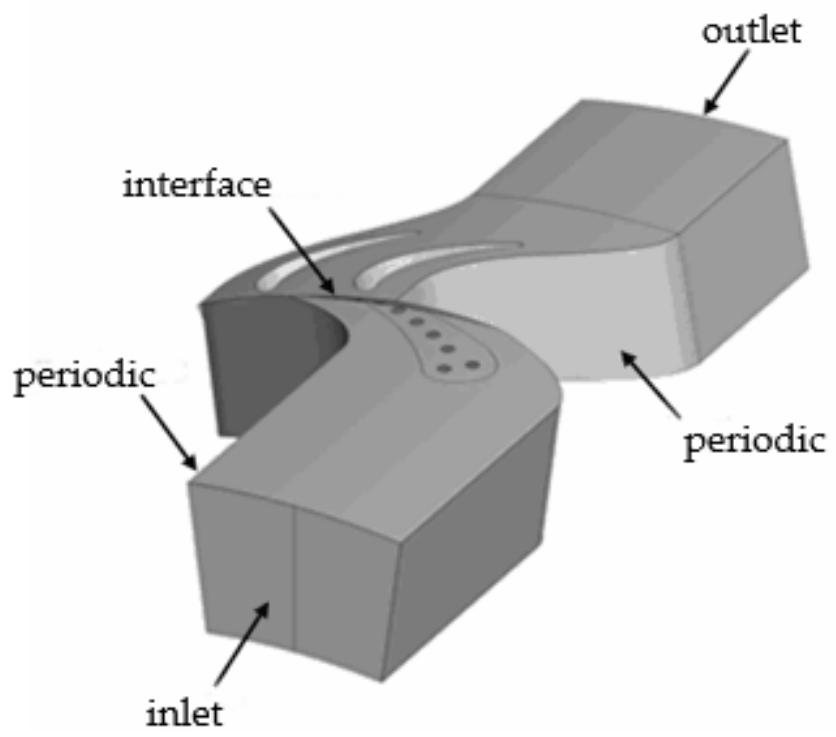

(a)

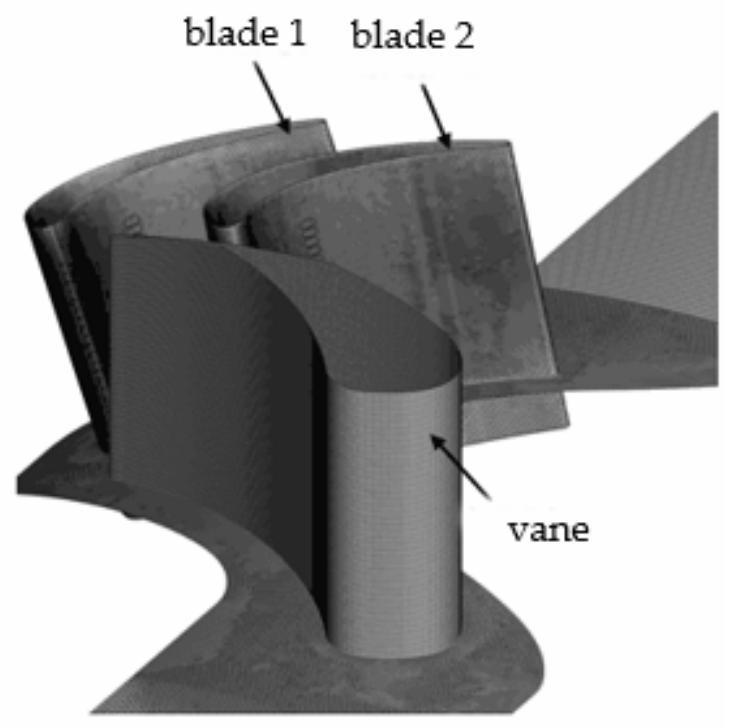

(b)

Figure 2. Computational domain and mesh. (a) Computational domain; (b) mesh. 
Table 3. Boundary conditions.

\begin{tabular}{cc}
\hline Parameter & Value \\
\hline Inlet total temperature of the mainstream (K) & 818 \\
Inlet total pressure of the mainstream $(\mathrm{kPa})$ & 213.28 \\
Turbulence intensity of the mainstream $(\%)$ & 8.0 \\
Mass-weight ratio of the LE cooling air $(\%)$ & 40 \\
Mass-weight ratio of the PS cooling air $(\%)$ & 35 \\
Mass-weight ratio of the SS cooling air $(\%)$ & 25 \\
Inlet total temperature of the cooling air (K) & 414 \\
Turbulence intensity of the cooling air $(\%)$ & 5 \\
\hline
\end{tabular}

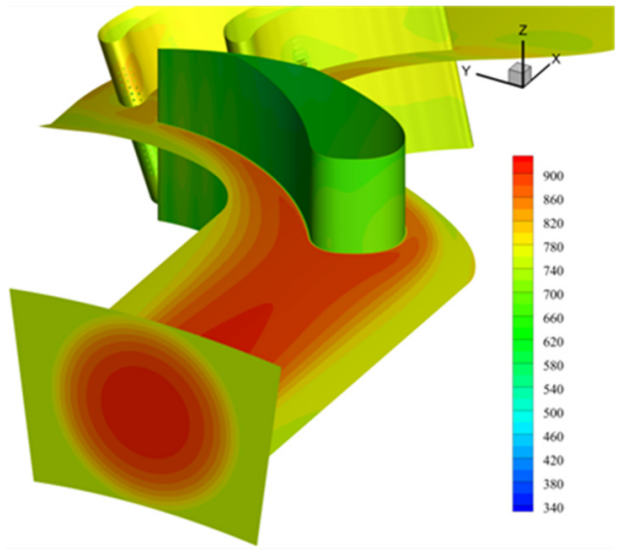

(a)

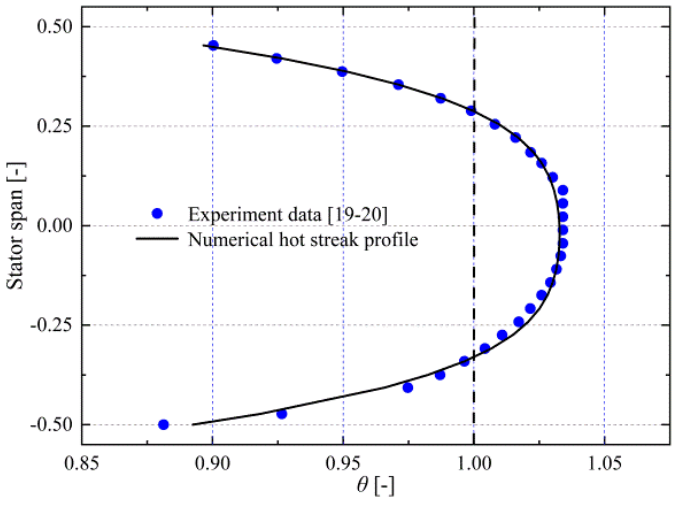

(b)

Figure 3. Temperature distribution of the turbine stage. (a) Temperature distribution; (b) temperature profile.

Firstly, three mesh strategies with 6.5, 8.5, and 9.5 million grid elements have been adopted to validate with experiment results [21]. The dimensionless temperature and total pressure distributions along the mid-span are shown in Figure 4. In Figure 4, the negative value in the $x$ abscissa represents the pressure side, while the positive value represents the suction side. The numerical results for the three mesh strategies show roughly the same changing trends as the experiment results, with maximum errors below 5\%. For the normalized pressure distribution, the numerical value is lower than the experimental results at the relative chord length of $x / C_{a x}=0.6-0.8$. For the normalized pressure distribution, the profile oscillates slightly at the relative chord length of $x / C_{a x}=0.5-1.0$. In summary, the grid independence is assured and the medium mesh can be employed in the following calculation. Then, the convergence result of the steady simulation is used as the initial values for the unsteady numerical simulation. Figure 5 shows the normalized pressure and temperature ratio convergence history of the unsteady numerical simulation. It can be observed that the change rule of the normalized pressure and temperature ratio is periodic with time after 4 stator periods, which indicates that the computation has been conducted for enough time steps for the convergence of unsteady simulation. Then, the numerical results of the rotor blade at four different relative stator-rotor locations $(t=0 / 4 T, 1 / 4 T$, $2 / 4 T$, and $3 / 4 T$, where the $T$ is the stator period) of the fifth stator period are investigated to reveal the combined effects of the hot streak and rotor-stator interaction. 


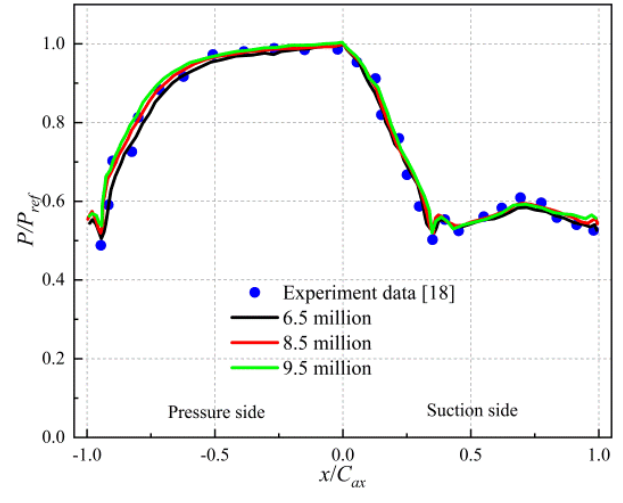

(a)

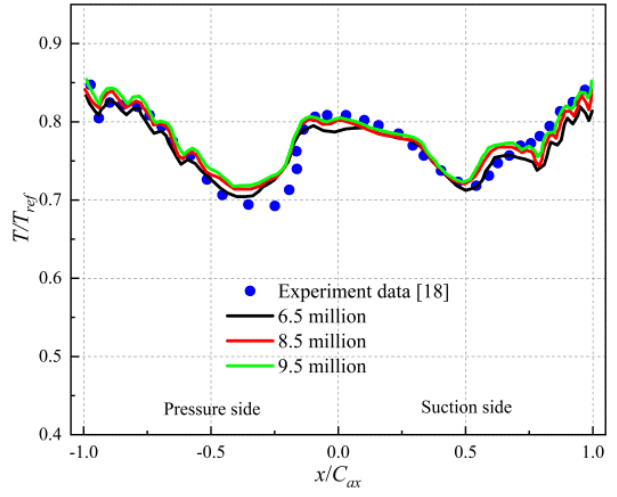

(b)

Figure 4. Grid independence test. (a) Pressure distribution; (b) temperature distribution.

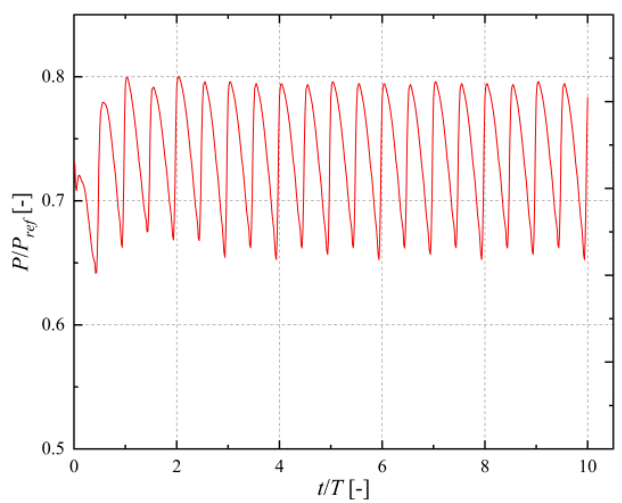

(a)

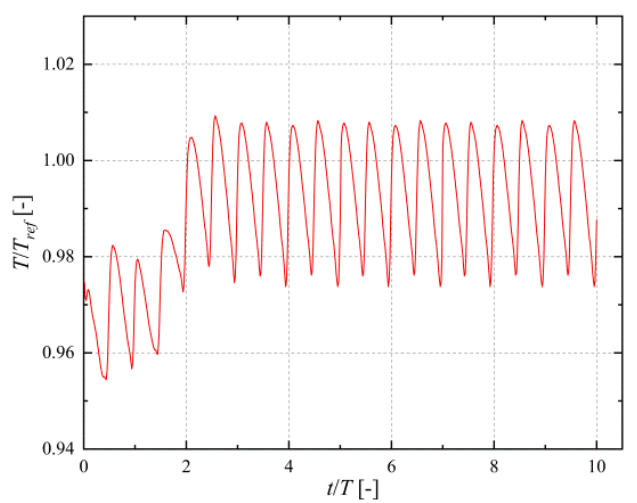

(b)

Figure 5. Normalized pressure and temperature ratio convergence history of the unsteady simulation. (a) Pressure ratio convergence history; (b) temperature ratio convergence history.

\subsection{Thermal Parameter Definition}

To analyze the cooling performance of the rotor blade, Equations (1)-(3) are used to explain the definitions of thermal parameters; see in Figure 6 [9].

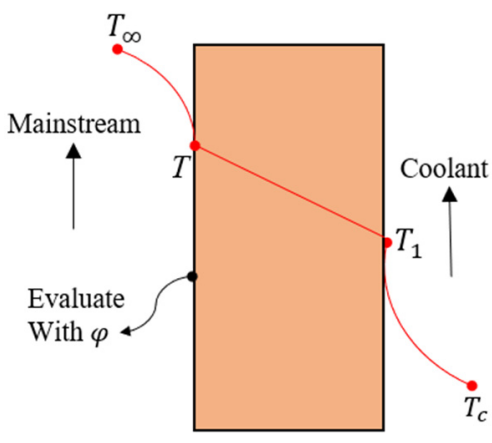

(a)

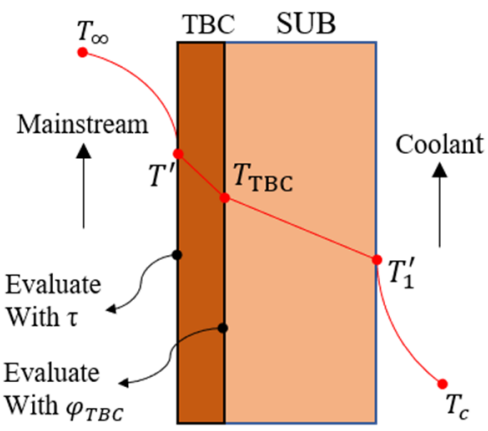

(b)

Figure 6. Thermal parameter definitions. (a) Uncoated rotor blade; (b) coated rotor blade.

To evaluate the cooling performance on the surface of the rotor blades, the overall cooling effectiveness of the uncoated rotor blade is defined as Equation (1).

$$
\varphi=\frac{T_{\infty}-T_{w}}{T_{\infty}-T_{\mathcal{c}}}
$$


where the $T_{w}$ is the temperature of the coupling surface between the external flow field and the blade; $T_{\infty}$ is the inlet total temperature, which is $818 \mathrm{~K}$ (see in Table 3 ); and $T_{\mathcal{C}}$ is the temperature of the cooling gas of the rotor blade, which is $414 \mathrm{~K}$ (see in Table 3) [16].

To evaluate the cooling performance of thermal barrier coatings, the overall cooling effectiveness of the coated rotor blade is defined as Equation (2).

$$
\varphi_{T B C}=\frac{T_{\infty}-T_{T B C}}{T_{\infty}-T_{C}}
$$

where $T_{T B C}$ is the temperature of the substrate metal surface.

To evaluate the influence of the additional thermal barrier coatings on the cooling performance, the increment in overall cooling effectiveness due to TBCs is defined as Equation (3).

$$
\delta \phi=\left(\frac{\phi_{T B C}-\phi}{\phi}\right) \times 100 \%
$$

\section{Discussion}

\subsection{Influence on the Cooling Performance of the Uncoated Stator Vane}

The numerical results at four different relative stator-rotor locations $(t=0 / 4 T, 1 / 4 T$, $2 / 4 T$, and $3 / 4 T$ ) are investigated in one stator period. In the initial state (the $0 / 4$ stator period), the trailing edge of the stator vane (vane 1) is located in front of the leading edge of the rotor blade (blade 2); see in Figure 7a. In the 2/4 stator period, the rotor blade (blade 3 ) rotates to the center of the vane passage; see in Figure 7a. In the 1/4 and 3/4 stator periods, the rotor blade rotates close to the suction side and the pressure side of the stator vane trailing edge (blade 1 and blade 2); see in Figure $7 \mathrm{~b}$. Since both the internal heat conduction and the convection heat transfer have been considered in the unsteady calculation, the temperature distribution of the numerical results can directly reflect the flow and heat transfer effects in the turbine stage. Figure 8 shows the total temperature distribution in the mid-span of the turbine stage at different relative stator-rotor locations. When the hot streak passes through the stator vane passage, the width of the hot streak is gradually narrowed due to the narrowing down of the vane passage. In addition, the temperature of the hot streak is gradually reduced due to its mixing with the surrounding stream at a lower temperature. Due to the convective heat transfer with the vane surface, the gas temperature of the unsteady wake is relatively lower than that of the mainstream. Figure 8 shows the overall cooling effectiveness distribution on the surface of the stator vane at different relative stator-rotor locations. It can be observed that there is no significant difference at different relative stator-rotor locations. Relatively lower overall cooling effectiveness can be observed close to the stagnation region of the leading edge where it is directly impinged by the hot streak. In comparison, relatively higher overall cooling effectiveness can be observed in the end-wall region due to the influence of the stream at a lower temperature near the hub and tip regions. In summary, the overall cooling effectiveness on the suction side is lower than that on the pressure side. In addition, relatively lower cooling effectiveness can be observed at the trailing edge, where it is difficult to design the cooling arrangements.

Figure 9 shows the overall cooling effectiveness distribution along the vane surface at planes of $25 \%$ span, $50 \%$ span, and $75 \%$ span. It can be observed that the variation in overall cooling effectiveness profiles has a relatively similar trend at different spans. A local minimum of overall cooling effectiveness is located near the $0.15 C_{a x}$ on the suction side. Further downstream, the effectiveness increases rapidly to the local maximum on both sides. On the pressure side, the local maximum effectiveness region is located in the region at the relative chord length of about $-0.5 C_{a x}$. On the suction side, the region is located at the relative chord length of about $0.7 C_{a x}$. Close to the trailing edge, the transition of the boundary layer leads to the rapid decline of and fluctuations in the cooling effectiveness profile. In summary, relatively higher cooling effectiveness can be observed in the region 
close to the cooling channel, while relatively lower values are located far away from the cooling channel.

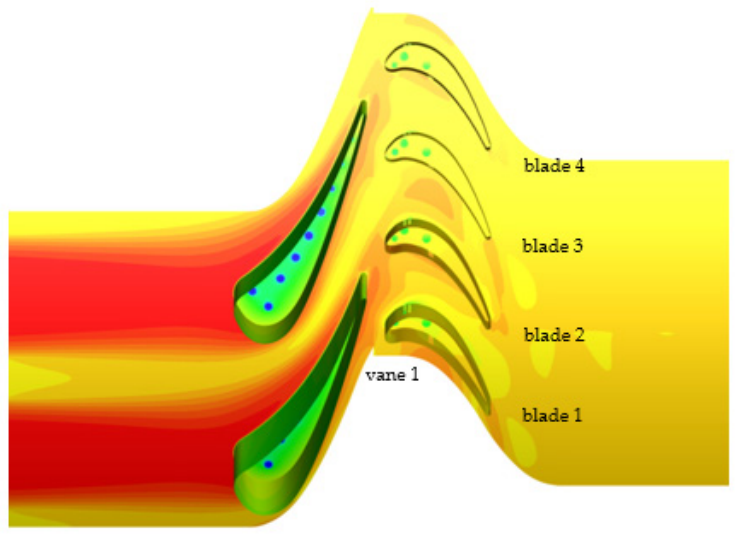

(a)

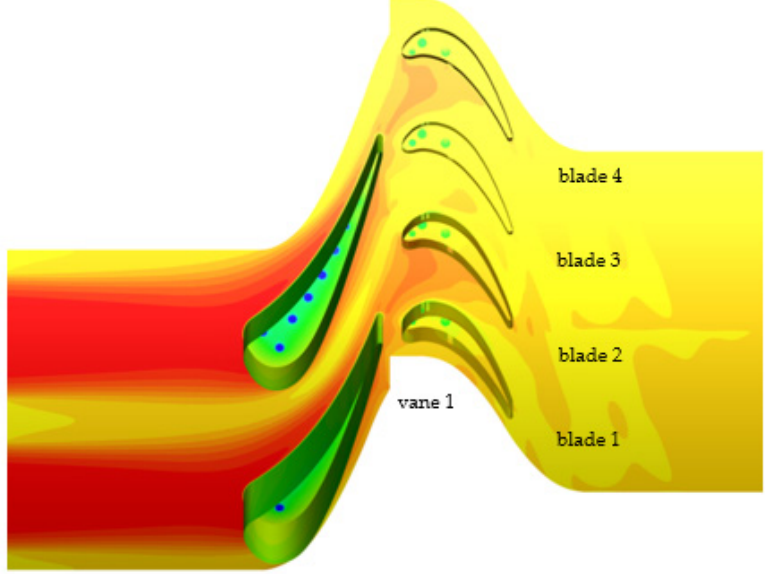

(b)

$\begin{array}{lllllllllllllll}T[\mathrm{~K}]: 340 & 380 & 420 & 460 & 500 & 540 & 580 & 620 & 660 & 700 & 740 & 780 & 820 & 860 & 900\end{array}$

Figure 7. Total temperature distribution in the mid-span. (a) At $t=0 / 4 T$; (b) at $t=1 / 4 T$.

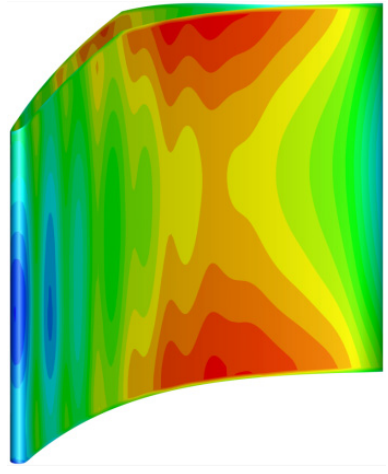

(a)

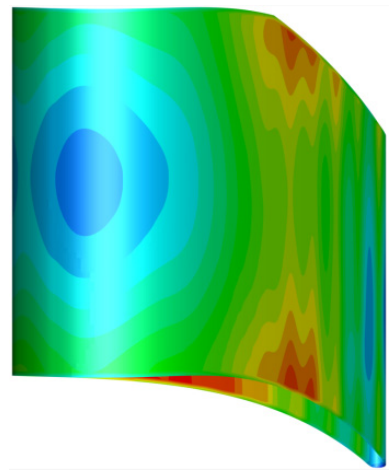

(e)

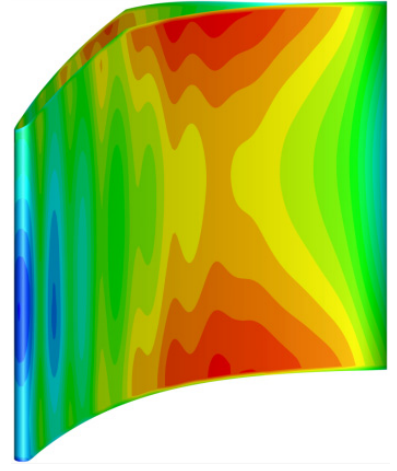

(b)

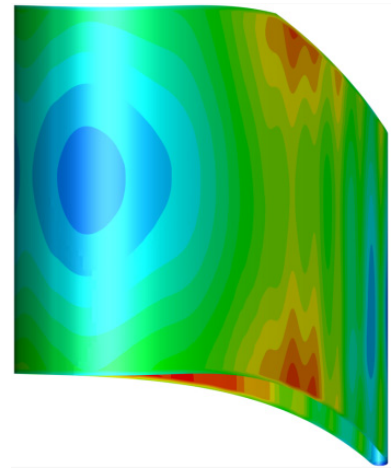

$(\mathbf{f})$

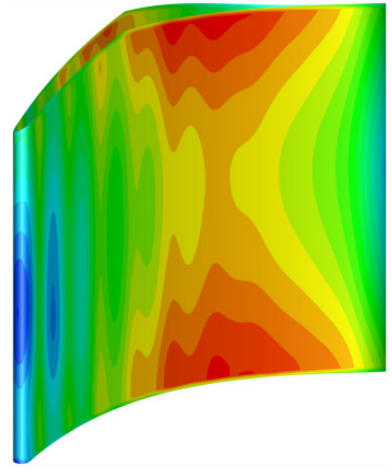

(c)

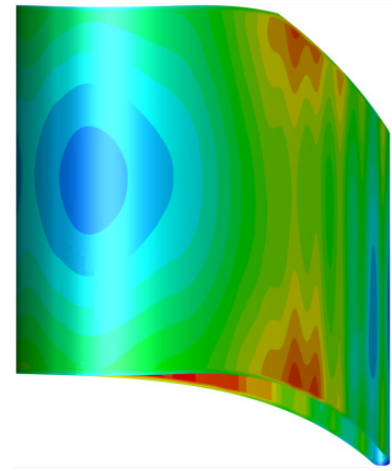

(g)

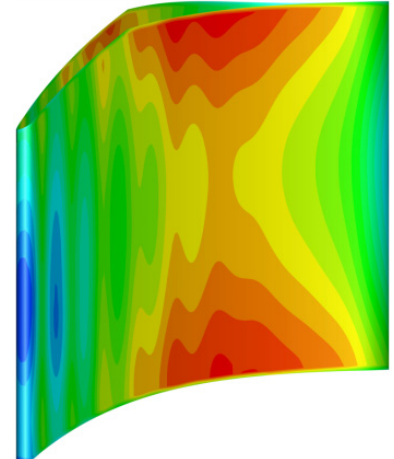

(d)

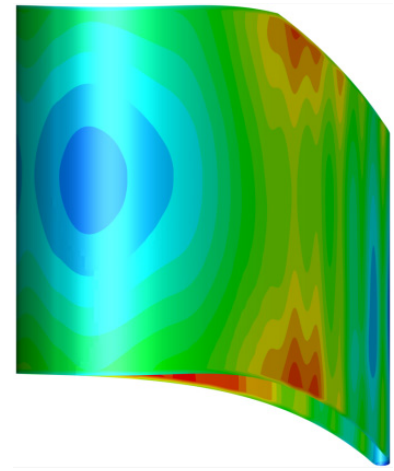

(h)

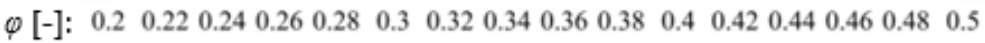

Figure 8. The overall cooling effectiveness of the stator vane at different relative stator-rotor locations. (a) Pressure Side At 0/4 T; (b) Pressure Side At 1/4 T; (c) Pressure Side At 2/4 T; (d) Pressure Side At 3/4 T; (e) Suction Side At 0/4 T; (f) Suction Side At 1/4 T; (g) Suction Side At 2/4 T; (h) Suction Side At $3 / 4 T$. 


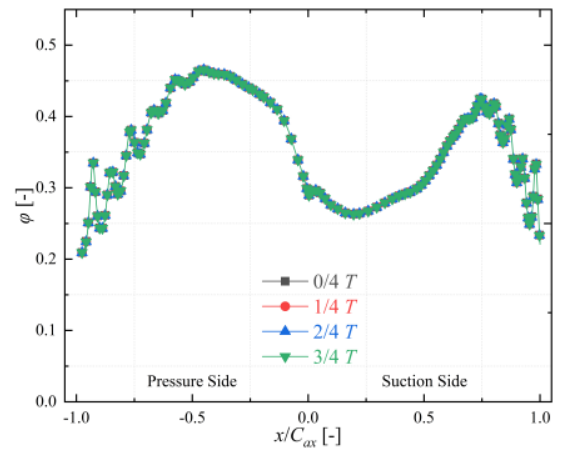

(a)

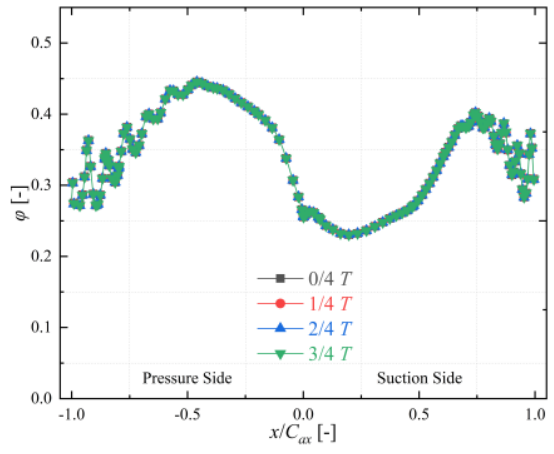

(b)

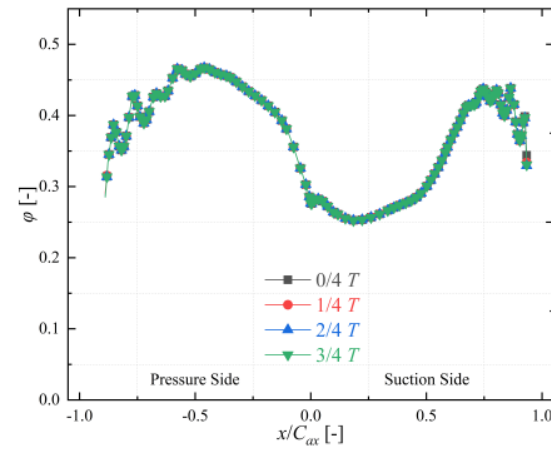

(c)

Figure 9. The overall cooling effectiveness distribution along the stator vane surface. (a) At 25\% span; (b) at $50 \%$ span; (c) at $75 \%$ span.

\subsection{Influence on the Cooling Performance of the Uncoated Rotor Blade}

Figure 10 shows the streamlined pattern of the cooling air ejected from the film cooling holes mounted on the leading edge, the pressure side, and the suction side at different relative stator-rotor locations. It can be observed that the cooling air exhausted from rows LE1 to LE2 passes downstream of the pressure side, while the cooling air from row LE3 flows toward the suction side at different relative stator-rotor locations. It can be noted that the mechanism of film cooling forms a protective cooling layer to defend the blade surface against the influence of the external high-temperature mainstream. After entering the rotor blade passage, the unsteady wake sweeps through the film cooling holes and thus exerts a significant effect on the film cooling flow field over the blade surface. In the initial state (the $0 / 4$ stator period), the trailing edge of the stator vane is located in front of the leading edge of the rotor blade. In the region close to the root region on the pressure side, the mainstream cannot effectively suppress the cooling air on the blade surface, which causes part of the cooling air to lift off from the blade surface and mix with the external mainstream. This phenomenon happens due to the low total pressure defection and velocity defection caused by unsteady wake transportation [11]. Further downstream, the shunting phenomenon is gradually suppressed, which leads to the reattachment of the cooling air on the blade surface. The influence of unsteady wake transportation only persists for a short period of time. On the pressure side of the leading edge, the influence of the unsteady wake transportation gradually weakens in the $2 / 4$ stator periods. In the $3 / 4$ stator period, the unsteady wake is transported to the suction side of the leading edge. It should be noted that the mainstream velocity on the suction surface is relatively higher than that on the pressure side [12]. Therefore, the unsteady wake transportation exerts a relatively insignificant impact on the film cooling coverage on this side. As time goes by, the unsteady wake is transported to the pressure side of the leading edge. The flow field of the mainstream and the film cooling air returns to the initial state.

Figure 11 shows the overall cooling effectiveness distribution of the uncoated rotor blade at different relative stator-rotor locations. Under the hot streak inlet condition, rotor-stator interaction exerts a significant effect on the cooling performance of the rotor blade. After passing through the interface of stator and rotor, the hot stream undergoes an obvious secondary flow process. The hot stream firstly migrates to the pressure side of the rotor blade and then is separated and transported to the pressure side and the suction side, respectively. This phenomenon can be described by the Kerrebrock and Mikolajczak segregation effect (K-M segregation effect) [12-14]. Relatively higher cooling effectiveness can be observed in the region close to the film cooling holes. Further downstream, the overall cooling effectiveness gradually decreases due to the mixing effect of the cooling air with the hot streak and the mainstream. Furthermore, relatively lower overall cooling effectiveness is located at the trailing edge. 


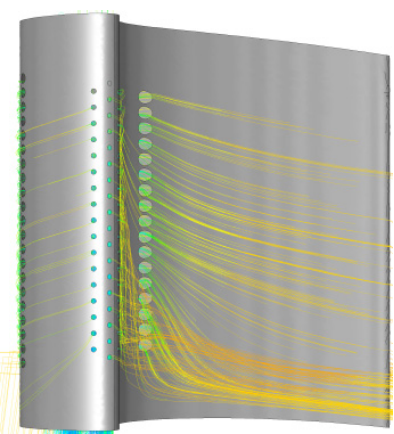

(a)

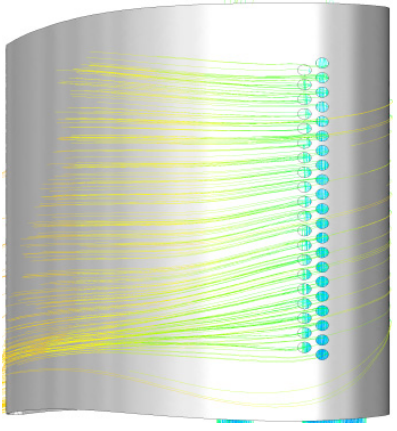

(e)

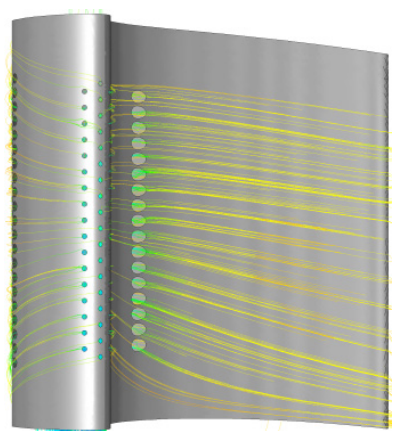

(b)

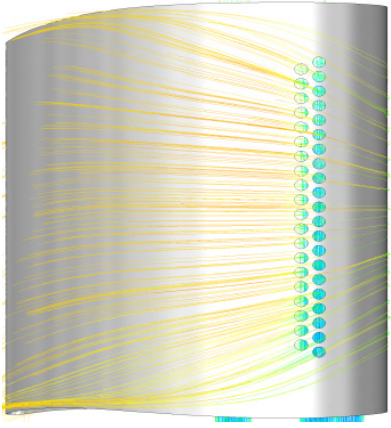

(f)

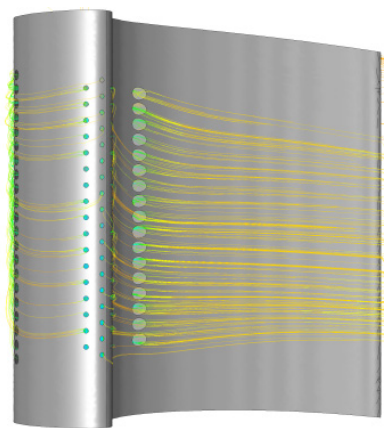

(c)

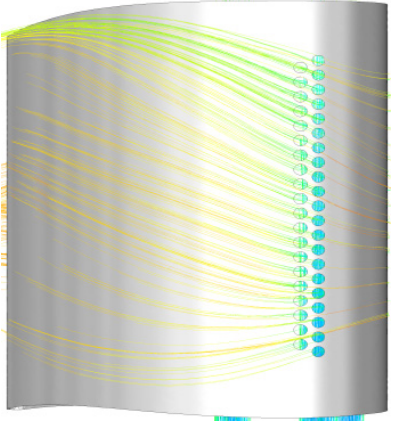

(g)

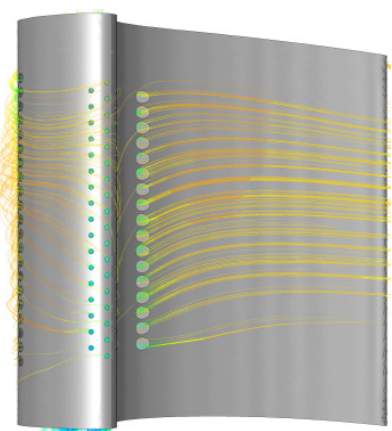

(d)

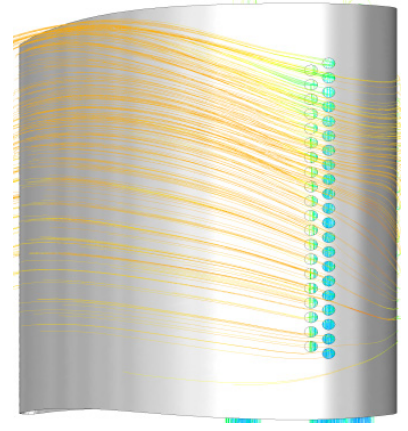

(h)

Figure 10. The streamlined pattern of the film cooling air at different relative stator-rotor locations. (a) Pressure Side At 0/4 T; (b) Pressure Side At 1/4 T; (c) Pressure Side At 2/4 T; (d) Pressure Side At 3/4 T; (e) Suction Side At 0/4 T; (f) Suction Side At 1/4 T; (g) Suction Side At 2/4 T; (h) Suction Side At $3 / 4 T$.

Comparing Figure 7 with Figure 11, it is clear that the trailing edge of the stator vane (vane 1) is located in front of the leading edge of the rotor blade (blade 2), which leads to relatively lower cooling performance on both sides of the rotor blade. Overall, the hot streak exerts a more obvious impact on the pressure side. In addition, it can be observed that the unsteady wake transportation exerts both positive and negative effects on the cooling performance of the rotor blade. On the one hand, the total pressure and velocity defection caused by unsteady wake transportation worsens the coverage of the film cooling and thus decreases the cooling performance, especially in the root regions on the pressure side. On the other hand, the lower gas temperature of the unsteady wake helps improve the cooling performance of the leading edge, especially in the region close to the stagnation line. It can be observed that there is an obvious drop in the cooling performance in the $1 / 4$ stator period. Comparing Figure 7 with Figure 11, it is clear that the affected region of the hot streak is enlarged and transported to the aft portion of the blade surface, which decreases the cooling performance on the pressure side. In the $2 / 4$ stator period, the rotor blade (blade 1) is located in the middle of the vane passage; see in Figure 7 . On the pressure side, part of the hot stream passes through rotor blade 1 and then migrates to the pressure side of blade 2 . The affected region is mainly located in the aft portion of the pressure side. On the suction side, a relatively lower gas temperature between the two hot streaks improves the cooling performance, especially on the leading edge. Compared with that in the $2 / 4$ stator period, the influence of the hot streak is further weakened in the $3 / 4$ stator period, especially on the pressure side. Therefore, the cooling effectiveness begins to increase and a relatively larger value can be observed in the $3 / 4$ stator period. 


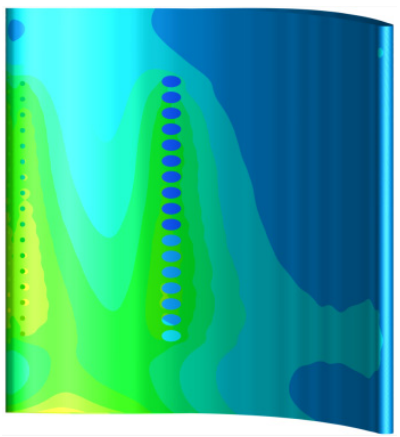

(a)

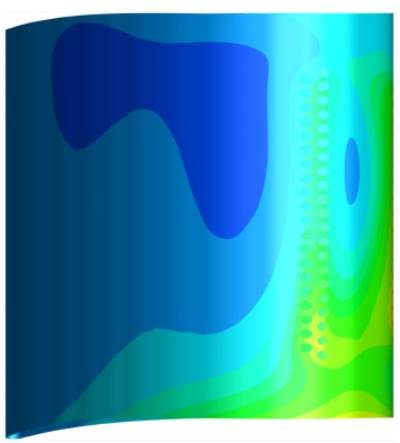

(e)

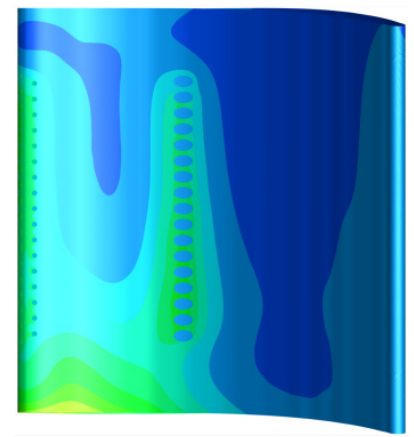

(b)

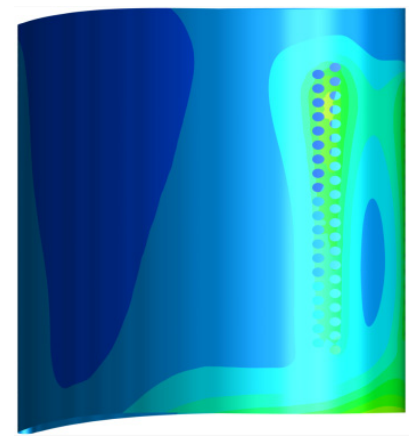

(f)

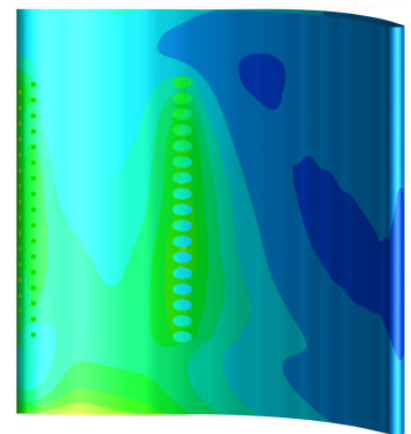

(c)

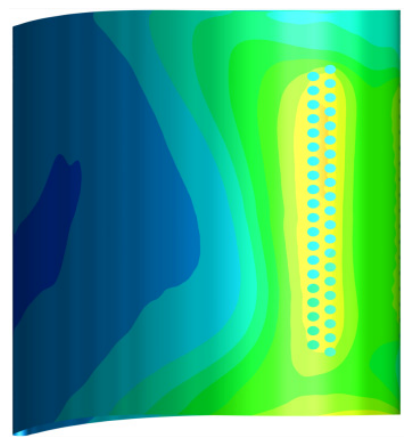

$(\mathrm{g})$

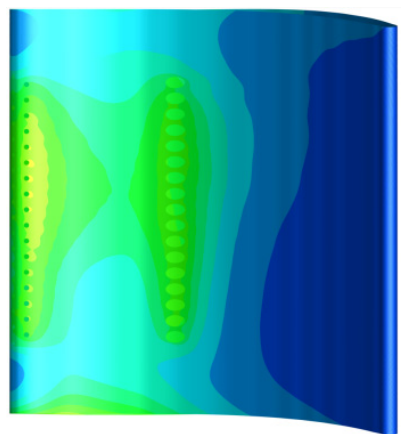

(d)

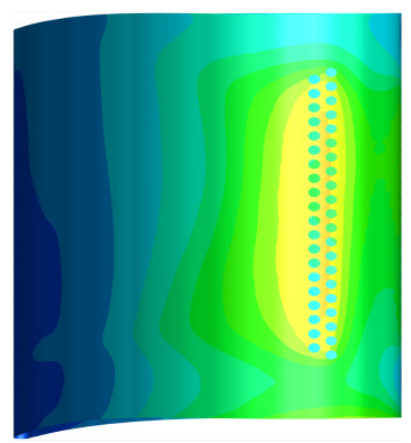

(h)

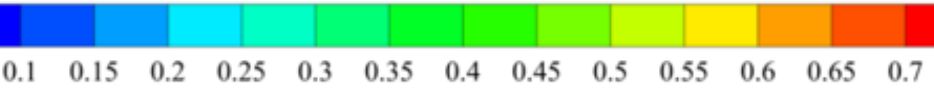

Figure 11. The overall cooling effectiveness of the uncoated blade at different relative stator-rotor locations. (a) Pressure Side At 0/4 T; (b) Pressure Side At $1 / 4 T$; (c) Pressure Side At 2/4 T; (d) Pressure Side At 3/4 T; (e) Suction Side At 0/4 T; (f) Suction Side At $1 / 4 T$; (g) Suction Side At 2/4 T; (h) Suction Side At $3 / 4 T$.

Figure 12 shows the overall cooling effectiveness distribution along the blade surface at planes of $25 \%$ span, $50 \%$ span, and $75 \%$ span. It can be observed that the overall cooling effectiveness profiles show a similar change trend at different spans. Relatively higher overall cooling performance can be observed close to the film cooling holes. In the region away from the film cooling holes, the overall cooling performance gradually decreases, especially at the trailing edge. On the pressure side, the local maximum can be observed near the stagnation line and the relative chord length of about $-0.40 C_{a x}$ when located close to the LE and PS film cooling holes on this side; see in Figure 1. On the suction side, a local maximum is observed near the relative chord length of about $0.20 C_{a x}$ when located in the vicinity of the SS film cooling holes. In the initial state (the $0 / 4$ stator period), relatively higher overall cooling effectiveness can be observed on the pressure side of the leading edge due to the lower temperature of the unsteady wake. On the pressure side, the overall cooling effectiveness is 0.407 at the $-0.40 C_{a x}$ of $50 \%$ span. On the suction side, the value decreases to 0.144 at the $0.40 C_{a x}$ of $50 \%$ span. In the $1 / 4$ stator period, there is an obvious drop in cooling effectiveness on both sides. Compared with that of the $0 / 4$ stator period, the cooling effectiveness decreases from 0.452 to 0.352 near the stagnation point on $50 \%$ span. In the $2 / 4$ stator period, a relatively large improvement in cooling effectiveness can be observed on the suction side in areas under the influence of a lower mainstream temperature between two adjacent hot streaks; see in Figure 7. Compared with that of the $1 / 4$ stator period, the overall cooling effectiveness increases from 0.309 to 0.398 at the $-0.40 C_{a x}$ of $50 \%$ span. On the suction side, the value increases from 0.153 to 0.295 at the $0.40 C_{a x}$ of $50 \%$ span. In the $3 / 4$ stator period, there is an obvious increase in the 
overall cooling effectiveness over the blade surface. Compared with that of the $2 / 4$ stator period, the overall cooling effectiveness increases from 0.398 to 0.424 at the $-0.40 C_{a x}$ on $50 \%$ span and from 0.295 to 0.419 at the $0.40 C_{a x}$ in areas close to the film cooling holes on the suction side.

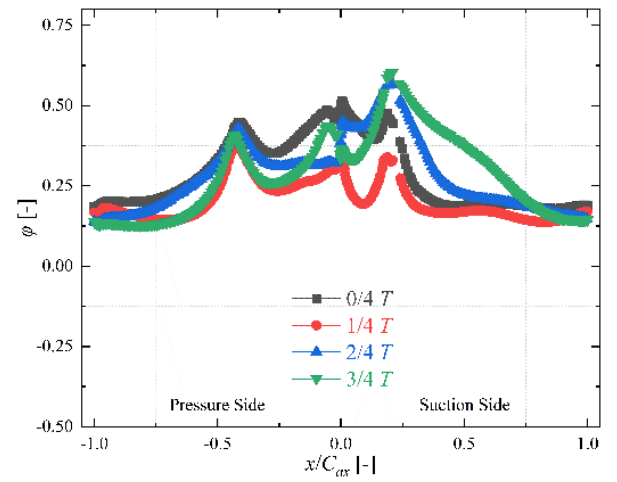

(a)

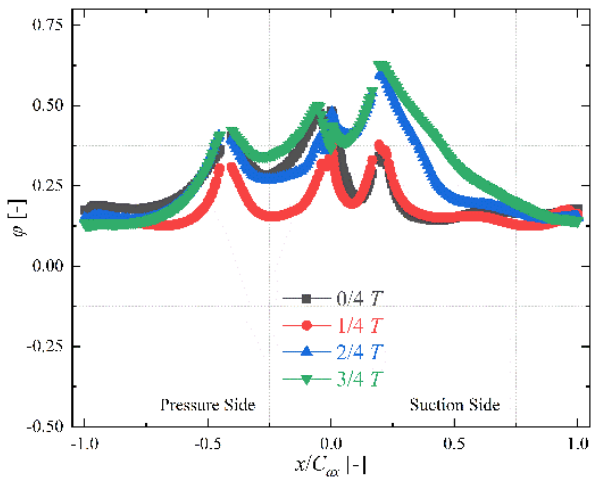

(b)

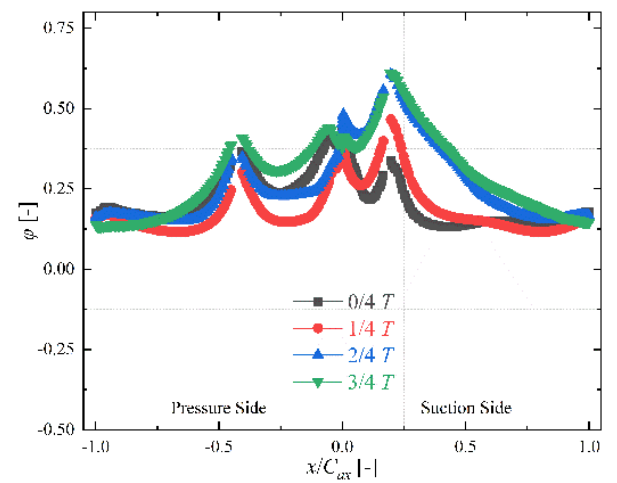

(c)

Figure 12. The overall cooling effectiveness distribution along the blade surface. (a) At $25 \%$ span; (b) at $50 \%$ span; (c) at $75 \%$ span.

In summary, the inlet hot streak exerts a significant impact on the cooling performance of the rotor blades. In one stator period, the relatively lower cooling performance of the rotor blade can be observed in the $1 / 4$ stator period. Then, the cooling performance begins to increase, where relatively higher cooling performance can be observed in the $3 / 4$ stator period. Unsteady wake transportation also exerts an impact on the cooling performance. In the initial state (the $0 / 4$ stator period), the unsteady wake transportation exerts a significant impact on the cooling air flow field close to the pressure side of the leading edge, which induces the cooling air to "lift off" and thus decreases the mass flow of the cooling air forming the cooling film. In the $3 / 4$ stator period, it also exerts an impact on the cooling air flow field close to the suction side of the leading edge. The mainstream velocity on the suction surface is relatively higher than that on the pressure side. Consequently, the unsteady wake exerts a relatively weak impact on film cooling.

\subsection{Influence on the Cooling Performance of the Coated Rotor Blade}

Figure 13 shows the overall cooling effectiveness distribution of the substrate metal surface of coated rotor blade at different relative stator-rotor locations. It can be observed that the overall cooling effectiveness distribution of the coated rotor blade is similar to that of the uncoated blades. In summary, an increase can be observed at different relative stator-rotor locations. In addition, relatively higher values can be observed close to the cooling film holes, while relatively lower values can be observed at the trailing edge. Furthermore, there is relatively higher cooling effectiveness on the root region of the blade, which decreases along with the height of the blade span. Figure 14 shows the increment in overall cooling effectiveness at different relative stator-rotor locations. Positive values can be observed on most parts of the coated blade surface, which indicates that the TBCs prevent the heat transfer from the mainstream to the blade surface, improving the overall cooling effectiveness. Relatively larger values can be observed in the regions downstream of the film cooling holes. A local minimum can be observed at the trailing edge. In addition, negative values even can be observed at the trailing edge. These phenomena happen because TBCs can show simultaneous positive and negative roles in improving the cooling performance of coated blades [15]. For the coated blade, the local maximum temperature gradient is located in the coating itself due to its lower thermal conductivity. In most parts of the blade, the substrate metal temperature is lower than that of the external mainstream. However, in the region with insufficient internal cooling, the substrate metal temperature 
may be higher than that of the external mainstream. In consequence, TBCs prevent the heat dissipation of the substrate where a negative value can be observed.

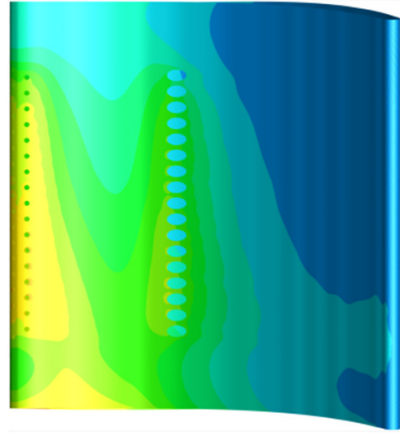

(a)

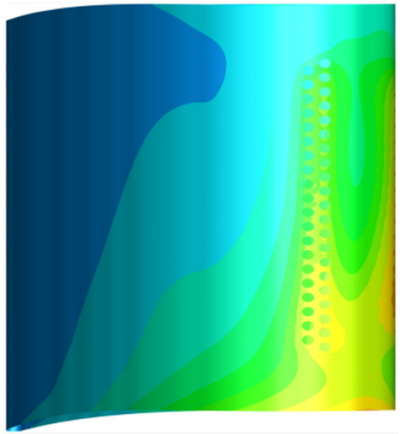

(e)

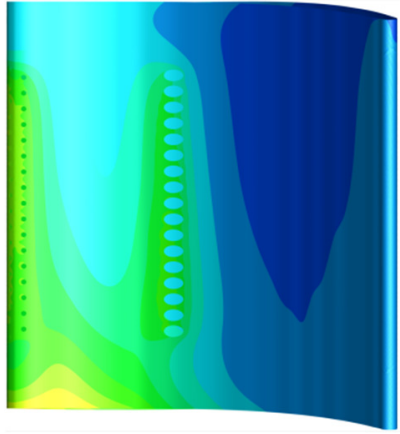

(b)

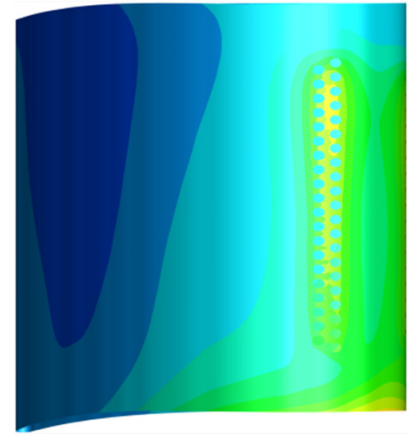

(f)

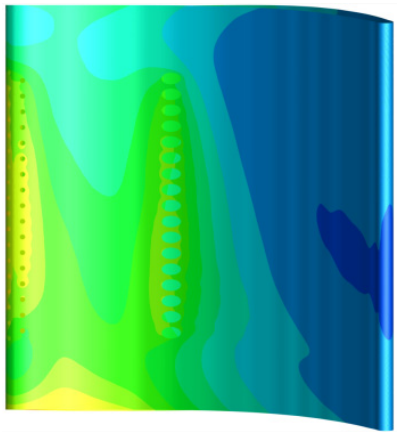

(c)

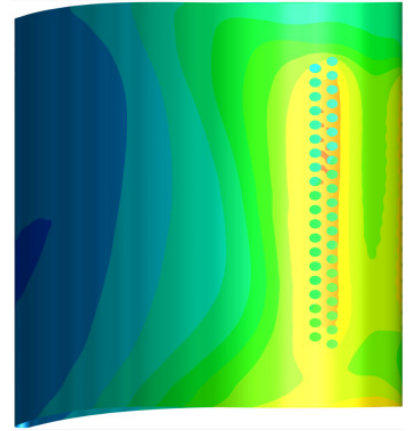

(g)

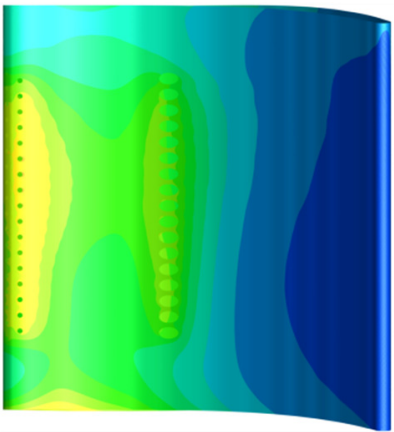

(d)

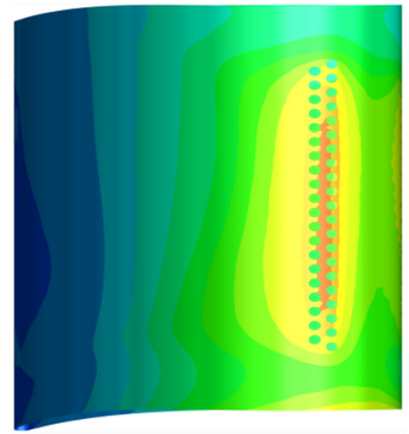

(h)

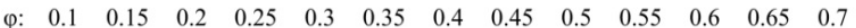

Figure 13. The cooling effectiveness of the coated blade at different relative stator-rotor locations. (a) Pressure Side At 0/4 T; (b) Pressure Side At 1/4 T; (c) Pressure Side At 2/4 T; (d) Pressure Side At 3/4 T; (e) Suction Side At 0/4 T; (f) Suction Side At 1/4 T; (g) Suction Side At 2/4 T; (h) Suction Side At $3 / 4 T$.

Figure 15 shows the overall cooling effectiveness distribution along the substrate metal surface at planes of $25 \%$ span, $50 \%$ span, and $75 \%$ span. It can be observed that the overall cooling effectiveness distribution of the coated blades is similar to that of the uncoated blades at different relative stator-rotor locations. On the pressure side, the local maximum effectiveness region can be observed near the stagnation line and relative chord length of $-0.40 C_{a x}$. On the suction side, the local maximum effectiveness region is located near the relative chord length of $0.20 C_{a x}$. In summary, the difference in cooling effectiveness decreases between different relative stator-rotor locations, which is beneficial for decreasing the thermal stress for the coated rotor blade. For the uncoated blade, the overall cooling effectiveness values are $0.407,0.309,0.398$, and 0.424 for different relative stator-rotor locations in the region near the relative chord length of $-0.40 C_{a x}$ on $50 \%$ span. In comparison, the cooling effectiveness changes to $0.464,0.397,0.466$, and 0.489 for the coated rotor blade at the same locations. Figure 16 shows the increment in the overall cooling effectiveness distribution at planes of $25 \%$ span, $50 \%$ span, and $75 \%$ span. A relatively higher increment in the overall cooling effectiveness can be observed close to the film cooling holes. Further downstream, the increment in the overall cooling effectiveness gradually decreases. Negative values can also be observed at the trailing edge. In addition, a relatively lower increment in the overall cooling effectiveness can be observed in the region with a relatively higher overall cooling effectiveness. Consequently, a relatively larger increment in the overall cooling effectiveness can be observed in the $1 / 4$ stator 
period, while smaller values are observed in the $3 / 4$ stator period. Regions with negative values can be observed at the trailing edge, especially for the blade in the $1 / 4$ stator period with relatively lower cooling performance. In the $1 / 4$ stator period, negative values can be observed between -0.8 and $-1.0 C_{a x}$ on the pressure side of the mid-span. On the suction side, negative values are located between 0.9 and $1.0 C_{a x}$ on the mid-span. Therefore, the internal heat transfer must be enhanced in the trailing edge regions in the cooling arrangement design process to maximize the insulation performance of TBCs for the coated rotor blade.

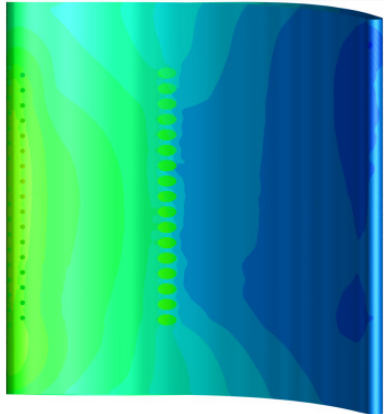

(a)

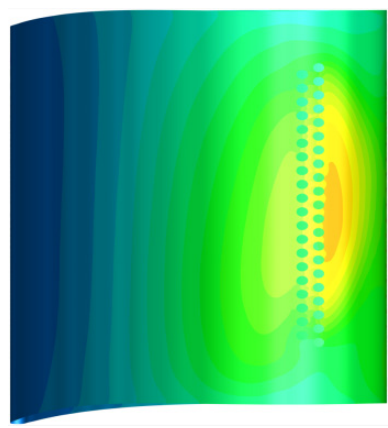

(e)

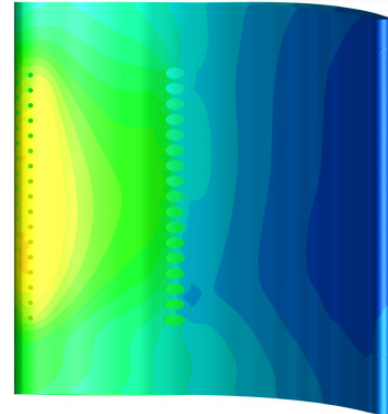

(b)

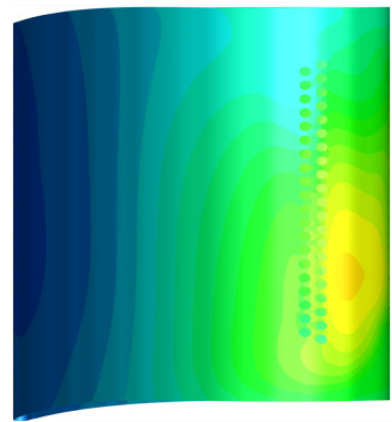

(f)

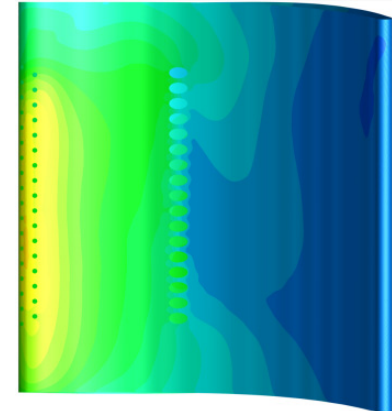

(c)

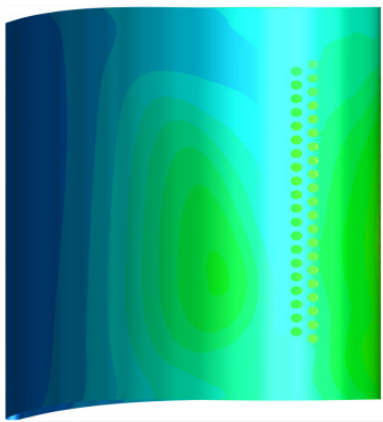

(g)

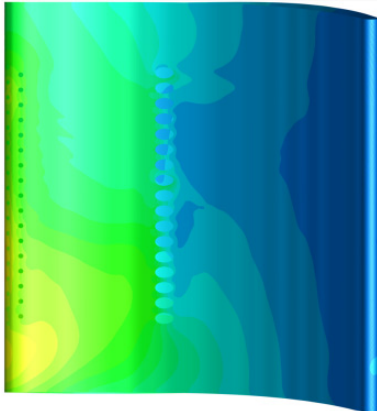

(d)

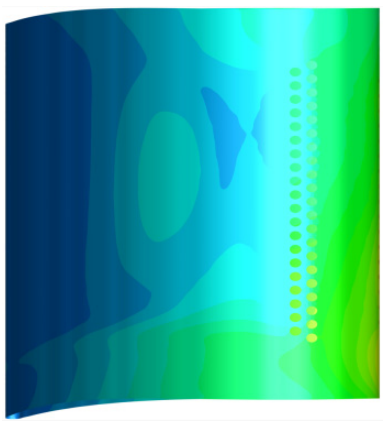

(h)

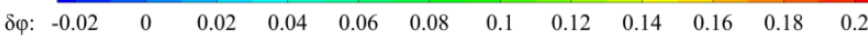

Figure 14. The increment in overall cooling effectiveness at different relative stator-rotor locations. (a) Pressure Side At 0/4 T; (b) Pressure Side At 1/4 T; (c) Pressure Side At 2/4 T; (d) Pressure Side At 3/4 T; (e) Suction Side At 0/4 T; (f) Suction Side At 1/4 T; (g) Suction Side At 2/4 T; (h) Suction Side At 3/4 T.

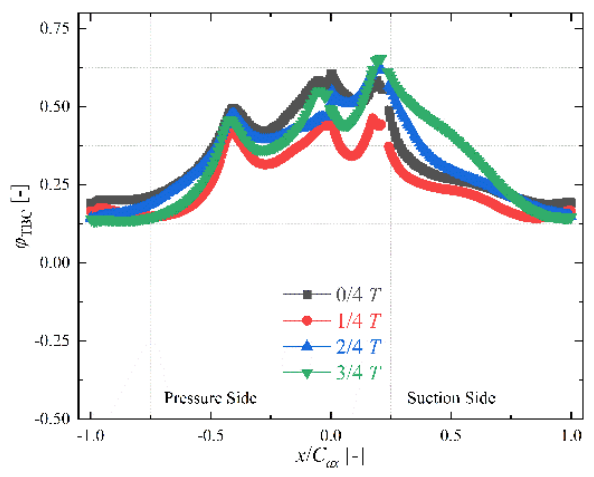

(a)

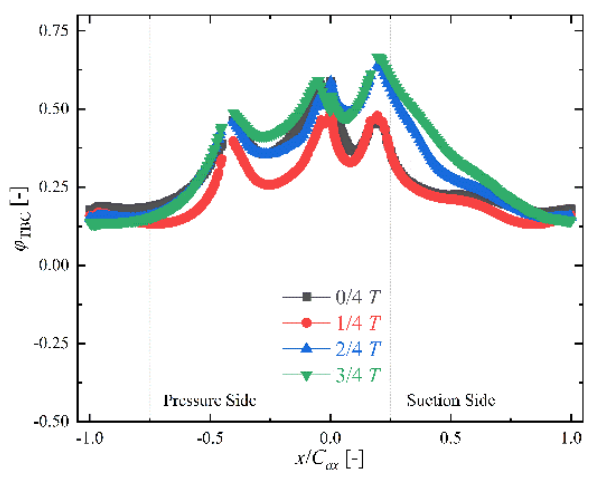

(b)

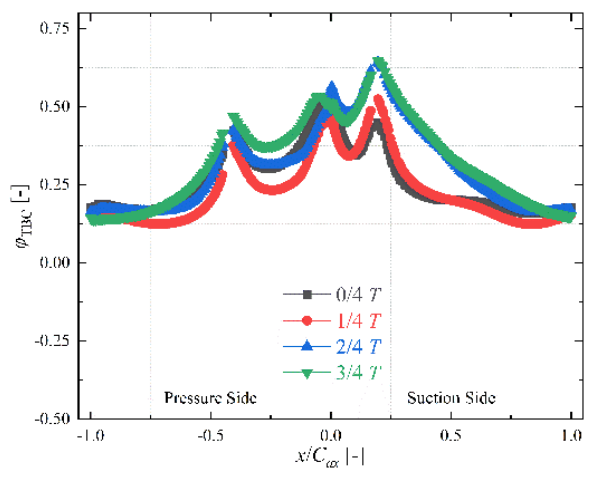

(c)

Figure 15. The cooling effectiveness distribution along the substrate metal surface. (a) At 25\% span; (b) at $50 \%$ span; (c) at $75 \%$ span. 


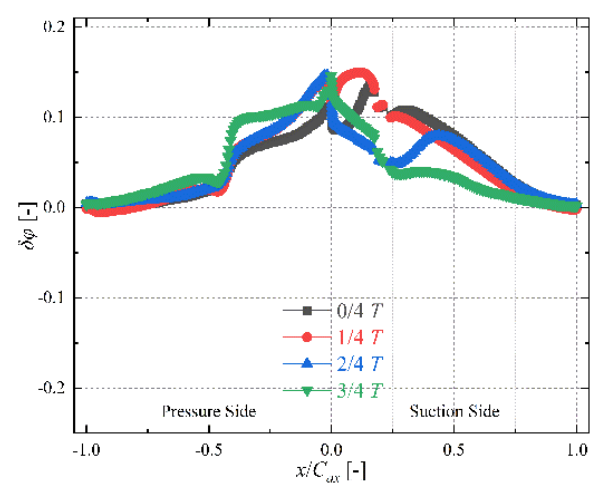

(a)

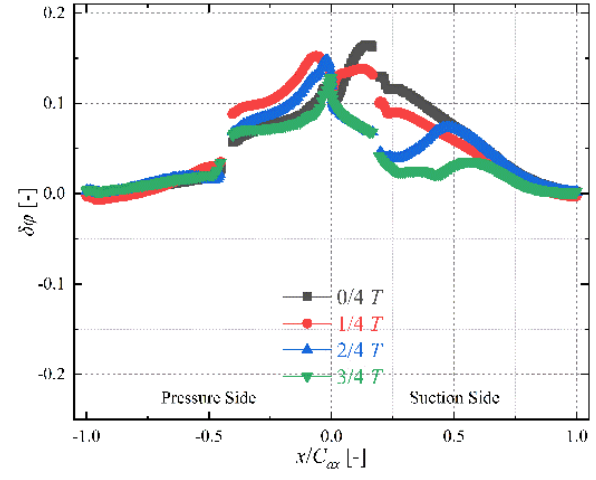

(b)

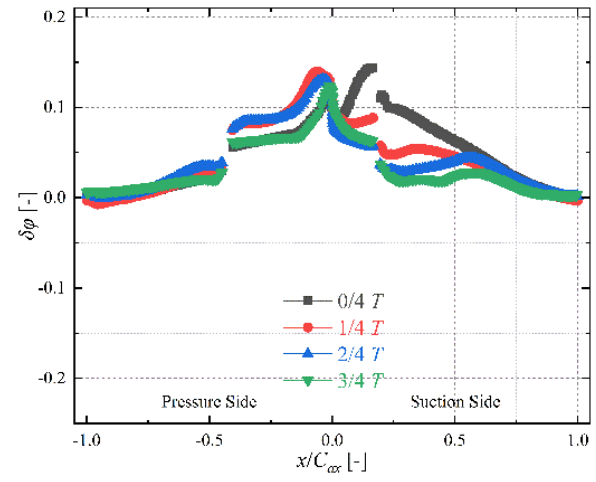

(c)

Figure 16. The increment in overall cooling effectiveness distribution along the blade surface. (a) At $25 \%$ span; (b) at $50 \%$ span; (c) at $75 \%$ span.

\section{Conclusions}

In this paper, the unsteady numerical calculation has been carried out to study the effect of rotor-stator interaction on the aerothermal and TBC insulation performance of a turbine stage under the hot streak inlet condition. The following conclusions can be drawn:

(1) Under the hot streak inlet conditions, the rotor-stator interaction basically does not affect the overall cooling effectiveness distribution on the stator vane surface. In comparison, it exerts a significant impact on the cooling performance of the rotor blades. Within one stator period, relatively lower cooling effectiveness of the blade can be observed in the $2 / 4$ stator period. Then, the overall cooling effectiveness begins to increase, where relatively higher values can be observed in the $3 / 4$ stator period. For the uncoated blade, the over cooling effectiveness values are $0.407,0.309,0.398$, and 0.424 for different relative stator-rotor locations near the relative chord length of $-0.40 C_{a x}$ on $50 \%$ span.

(2) In the initial state (the $0 / 4$ stator period), the unsteady wake transportation exerts a significant impact on the cooling air flow field close to the pressure side of the leading edge. In the 3/4 stator period, it exerts a significant impact on the cooling air close to the suction side of the leading edge, which induces the cooling air to "lift off" and thus decreases the mass flow of the cooling air, which leads to the film cooling over the blade surface. The unsteady wake exerts a relatively weak impact on the film cooling on the suction side due to a relatively higher velocity of the mainstream.

(3) Within one stator period, a relatively lower increment in the overall cooling effectiveness of the coated rotor blade can be observed in the $3 / 4$ stator period. Regions with negative values can be observed at the trailing edge. In the $1 / 4$ stator period, negative values can be observed between -0.8 and $-1.0 C_{a x}$ on the pressure side of the mid-span. On the suction side, negative values are located between 0.9 and $1.0 C_{a x}$ on the mid-span. Therefore, the internal heat transfer must be enhanced in those regions in the cooling arrangement design process to maximize the insulation performance of TBCs for the coated rotor blade.

Author Contributions: L.S. carried out the simulation and wrote this paper. Y.L. and H.H. improved the discussions and the paper overall. All authors have read and agreed to the published version of the manuscript.

Funding: This research was funded by the National Natural Science Foundation of China, grant number 51806184, and the Natural Science Foundation of Hunan Province, Grant No.: 2019JJ50590.

Institutional Review Board Statement: Not applicable.

Informed Consent Statement: Not applicable.

Data Availability Statement: Data is contained within the article. 
Conflicts of Interest: The authors declare no conflict of interest.

\section{Nomenclature}

\begin{tabular}{|c|c|}
\hline$x, y, z$ & Cartesian coordinates $(\mathrm{mm})$ \\
\hline$C_{a x}$ & Axial chord (mm) \\
\hline$x / C_{a x}$ & Relative chord length \\
\hline$p$ & Pressure $(\mathrm{Pa})$ \\
\hline$T_{\infty}$ & Inlet temperature $(\mathrm{K})$ \\
\hline$T_{C}$ & Temperature of the cooling gas in the cooling channel $(\mathrm{K})$ \\
\hline$T_{w}$ & Temperature of the coupling surface $(\mathrm{K})$ \\
\hline$T_{T B C}$ & Metal surface temperature with a TBC (K) \\
\hline$T_{w}$ & Vane local wall temperature $(\mathrm{K})$ \\
\hline$T_{\infty}$ & Inlet temperature of the mainstream $(\mathrm{K})$ \\
\hline$T^{\prime}$ & Surface temperature outside the coating $(\mathrm{K})$ \\
\hline$T$ & The stator period \\
\hline$T_{u}$ & Uniform turbulence intensity \\
\hline$\varphi$ & Overall cooling effectiveness \\
\hline$\varphi_{\mathrm{TBC}}$ & Overall cooling effectiveness of the coated blade \\
\hline$\Delta \varphi$ & Overall cooling effectiveness increment due to coating \\
\hline $\begin{array}{l}\text { Greek letters } \\
\varphi \\
\text { Abbreviations }\end{array}$ & Temperature ratio \\
\hline NGV & Nozzle stator vane \\
\hline TBC & Thermal barrier coating \\
\hline HS & Hot streak \\
\hline $\mathrm{CHT}$ & Conjugate heat transfer \\
\hline LE & Leading edge \\
\hline PS & Pressure side \\
\hline SS & Suction side \\
\hline
\end{tabular}

\section{References}

1. Qureshi, I.; Smith, A.D.; Povey, T. HP vane aerodynamics and heat transfer in the presence of aggressive inlet swirl. J. Turbomach. 2013, 135, 021040. [CrossRef]

2. Laskowski, G.M.; Tolpadi, A.K.; Ostrowski, M.C. Heat transfer predictions of film cooled stationary turbine airfoils[C]//Turbo Expo: Power for Land, Sea, and Air. Turbo Expo 2007, 47934, 475-485.

3. Gomes, R.A.; Niehuis, R. Film cooling effectiveness measurements with periodic unsteady inflow on highly loaded blades with main flow separation. J. Turbomach. 2011, 133, 021019. [CrossRef]

4. Padture, N.P.; Gell, M.; Jordan, E.H. Thermal barrier coatings for gas-turbine engine applications. Science 2002, 296, 280-284. [CrossRef]

5. Feuerstein, A.; Knapp, J.; Taylor, T.; Ashary, A.; Bolcavage, A.; Hitchman, N. Technical and economical aspects of current thermal barrier coating systems for gas turbine engines by thermal spray and EBPVD: A review. J. Therm. Spray Technol. 2008, 17, 199-213 [CrossRef]

6. Prapamonthon, P.; Xu, H.; Yang, W. Numerical study of the effects of thermal barrier coating and turbulence intensity on cooling performances of a nozzle guide vane. Energies 2017, 10, 362. [CrossRef]

7. Wang, Z.; Zhang, W. Numerical study on unsteady film cooling performance of turbine rotor considering influences of inlet non-uniformities and upstream coolant. Aerosp. Sci. Technol. 2021, 119, 107089. [CrossRef]

8. Liu, J.H.; Liu, Y.B.; He, X.; Liu, L. Study on TBCs insulation characteristics of a turbine blade under serving conditions. Case Stud. Therm. Eng. 2016, 8, 250-259. [CrossRef]

9. Prasert, P.; Soemsak, Y.; Suwin, S.; Daniele, D.; Huazhao, X.; Jianhua, W. Investigation of cooling performances of a non-film-cooled turbine vane coated with a thermal barrier coating using conjugate heat transfer. Energies 2018, 11, 1000.

10. Tang, W.Z.; Yang, L.; Zhu, W. Numerical simulation of temperature distribution and thermal-stress field in a turbine blade with multilayer-structure TBCs by a fluid-solid coupling method. J. Mater. Sci. Technol. 2016, 32, 452-458. [CrossRef]

11. Shi, L.; Sun, Z.Y.; Lu, Y.F. The Combined influences of film cooling and thermal barrier coatings on the cooling performances of a film and internal cooled vane. Coatings 2020, 10, 861. [CrossRef]

12. Wang, Z.; Wang, D.; Wang, Z.; Feng, Z. Heat transfer analyses of film-cooled HP turbine vane considering effects of swirl and hot streak. Appl. Therm. Eng. 2018, 142, 815-829. [CrossRef]

13. Wang, J.; Ge, N.; Sheng, C. Analysis of swirling flow effects on the characteristics of unsteady hot-streak migration. Chin. J. Aeronaut 2016, 29, 1469-1476. [CrossRef] 
14. Mansouri, Z.; Belamadi, R. The influence of inlet swirl intensity and hot-streak on aerodynamics and thermal characteristics of a high pressure turbine vane. Chin. J. Aeronaut 2021, 34, 66-78. [CrossRef]

15. Basol, A.M.; Jenny, P.; Ibrahim, M. Hot streak migration in a turbine stage: Integrated design to improve aerothermal performance. J. Eng. Gas Turb. Power 2011, 133, 44-53. [CrossRef]

16. Wang, Z.; Liu, Z.; Feng, Z. Influence of mainstream turbulence intensity on heat transfer characteristics of a HP turbine Stage with inlet hot streak[C]//Turbo Expo: Power for Land, Sea, and Air. Am. Soc. Mech. Eng. 2015, 56727, V05BT13A010.

17. Wang, Z.; Wang, D.; Liu, Z. Numerical analysis on effects of inlet pressure and temperature non-uniformities on aero-thermal performance of a HP turbine. Int. J. Heat Mass Tran. 2017, 104, 83-97. [CrossRef]

18. Xie, G.; Tao, Z.; Zhou, Z. Hole arrangement effect to film cooling performance on leading edge region of rotating blade. Int. J. Therm. Sci. 2021, 169, 107034. [CrossRef]

19. Zhao, W.; Chi, Z.; Zang, S. Scaling criteria accuracy for turbine blade film cooling effectiveness at unmatched temperature ratio conditions. Appl. Therm. Eng. 2021, 197, 117363. [CrossRef]

20. Shi, L.; Huang, H.; Lu, Y.F. The combined influences of hot streak and swirl on the cooling performances of C3X stator vane with or without TBCs. Coatings 2021, 11, 688. [CrossRef]

21. Hylton, L.D.; Mihelc, M.S.; Turner, E.R.; Nealy, D.A.; York, R.E. Analytical and Experimental Evaluation of the Heat Transfer Distribution over the Surfaces of Turbine Vanes; NASA Technical Report; NASA-CR-168015; NASA Lewis Research Center: Cleveland, OH, USA, 1982.

22. Hylton, L.D.; Nirmalan, V.; Sultanian, B.K.; Kauffman, R.M. The Effects of Leading Edge and Downstream Film Cooling on Turbine Vane Heat Transfer; NASA Technical Report; NASA-CR-182133; NASA: Washington, DC, USA, 1988.

23. Ke, Z.; Wang, J.-H. Conjugate heat transfer simulations of pulsed film cooling on an entire turbine vane. Appl. Therm. Eng. 2016, 109, 600-609. [CrossRef]

24. Wang, T.; Xuan, Y.; Han, X. Analysis of transient radiation-convection coupled effects on the HP turbine blade heat load with hot streak inlet. Appl. Therm. Eng. 2018, 138, 705-721. [CrossRef]

25. Camci, C.; Arts, T. An Experimetal convective heat transfer investigation around a film cooled gas turbine blade. J. Turbomach 1990, 112, 497-503. [CrossRef]

26. Li, Y.; Su, X.; Yuan, X. The effect of mismatching between combustor and HP vanes on the aerodynamics and heat load in a 1-1/2 stages turbine. Aerosp. Sci. Technol. 2020, 86, 78-92. [CrossRef] 